\title{
A Vigilância Epidemiológica diante do Sars-Cov-2: desafios para o SUS e a Atenção Primária à Saúde
}

Maria Aparecida Turci, Julia Braga Holliday, Nerice Cristina Ventura Costa de Oliveira

\section{RESUMO}

Este artigo recupera a linha do tempo da Covid no mundo e no Brasil, apresenta as características do agente patogênico e o seu impacto no perfil de expansão da doença. Discute possíveis limites e problemas na ação da Vigilância Epidemiológica do SUS (Sistema Único de Saúde) no enfrentamento da pandemia da COVID-19 e coteja com os limites colocados para uma maior participação da Atenção Primária à Saúde (APS) no controle da doença.

Palavras-chave: COVID-19; Pandemia; Atenção Primária à Saúde; Vigilância Epidemiológica.

Publicada em: 15/04/2020

DOI:10.14295/aps.v2i1.70

Maria Aparecida Turci

(Universidade José do Rosário Vellano/UNIFENAS, Brasil);

Julia Braga Holliday (Universidade José do Rosário Vellano/UNIFENAS, Brasil);

Nerice Cristina Ventura

\section{ABSTRACT}

This article recovers Covid's timeline aroud the world and in Brazil, presents Sars-Cov-2 characteristics and its impact on the patterns of the disease's expansion. It discusses limits and problems in the action of the Epidemiological Surveillance of SUS (Unified Health System) in facing the pandemic of COVID-19 and analyses the limits for a greater participation of Primary Health Care (PHC) in the control of the disease.

Costa de Oliveira

(Universidade José do Rosário Vellano/UNIFENAS, Brasil).

Correspondência para: Maria Aparecida Turci mariaturci@gmail.com

Keywords: COVID-19; Pandemic; Primary Health Care; Epidemiological Surveillance. 


\section{INTRODUÇÃO}

Em fevereiro de 2018, a Organização Mundial de Saúde (OMS) divulgou a lista atualizada de agentes patogênicos prioritários, que poderiam causar emergências de saúde pública e para as quais não existiam medidas suficientes de contenção, como drogas ou vacinas. Essa lista é elaborada e atualizada periodicamente, visando a aceleração de pesquisas. Junto com a Febre do Congo, de Marburgo, de Lassa, o Ebola, vírus zika, dentre outras, estava a Doença X. Segundo a OPAS (2018), a doença $X$ representava o conhecimento de que uma epidemia internacional grave poderia ser causada por um patógeno desconhecido, que provocaria doenças humanas e para o qual o mundo deveria se preparar antecipadamente.

Então, em dezembro de 2019, a China comunicou à OMS a ocorrência de casos atípicos de pneumonia em Wuhan, província de Hubei (WHO, 2020). Ainda na primeira semana de janeiro, as autoridades chinesas confirmaram se tratar de um novo agente patogênico: um coronavírus, posteriormente denominado SarsCov-s e a doença Covid19.

A última pandemia, provocada por nova cepa do vírus Influenza A subtipo H1N1, teve início no México em 2009 e até o seu fim, em agosto de 2010, havia contaminado meio milhão de pessoas (DAWOOD et al., 2012). Os alertas sobre o perigo iminente do surgimento de um novo patógeno parecem não ter preparado a saúde pública mundial para o que estava por vir.

As características do novo agente dão a dimensão do desafio. A velocidade de propagação do vírus (R0) tem sido estimada entre 2,0 até 6,47 em alguns modelos (WU et al., 2020). Transmitido por contato próximo, o vírus é liberado nas secreções do portador por meio de gotículas de saliva e secreção respiratória (LEUG et al., 2020; LIU et al., 2020a; SANTARPIA et al., 2020), que, por meio da tosse, espirro ou fala, atingem a mucosa da boca, nariz ou olhos do suscetível. O tempo de permanência do SarsCov em superfícies (DOREMALEN et al., 2020; KAMPF et al., 2020) dá sustentação à possibilidade de transmissão indireta, com potencial ainda por esclarecer. O período de incubação médio foi estimado em 5 dias (LAUER et al., 2020) com transmissão durante esse período descrita. Estima-se que em torno de $30 \%$ da população exposta não apresentará sintomas, $55 \%$ terão sintomas leves a moderados, $10 \%$ ficarão em estado grave e $5 \%$ necessitarão de cuidados intensivos (FERGURSON et al., 2020). A carga viral dos casos graves, que necessitam de hospitalização e cuidados de UTI, é mais alta. (LIU et al., 2020b). A taxa de letalidade, segundo dados do Worldometers, era de 5,7\% em 7 de março de 2020 (WORLDOMETER, 2020), mas dados provenientes dos pacientes do navio Diamond Princess sugerem que a letalidade numa população será de 1,1\% (RUSSEL et al., 2020). A letalidade se apresenta maior entre pacientes acima dos 60 anos e mais baixa entre os mais jovens, assim como a virulência.

Após o crescimento exponencial do número de casos na província de Hubei, na China, ainda em janeiro, surgiram os primeiros casos da Covid19 na Tailândia, Malásia, Austrália, Singapura, Filipinas, Vietnã, Japão e Coréia do Sul. Fora da Ásia, foram identificados casos nos Estados Unidos, Alemanha, França e Canadá. Dessa forma, no fim de janeiro, a OMS declarou a Covid19 uma emergência em saúde pública (OPAS, 2020b). Em fevereiro, foram registradas epidemias de Covid19 em vários países: Coréia do Sul, Irã e Itália. O início de março foi marcado pelo aumento de casos na Espanha e na Itália, que colocou 60 milhões de pessoas em quarentena. Em 11 de março de 2020, a Covid19 foi declarada uma pandemia (OPAS, 2020a) e, em 13 de março, uma emergência nacional nos Estados Unidos. (BRASIL, 2020b)

\section{A ORGANIZAÇÃO DO SUS PARA O ENFRENTAMENTO À COVID-19}

A primeira manifestação do sistema de vigilância do Sistema Único de Saúde (SUS) sobre a Covid se deu a partir da publicação de boletim epidemiológico, que comunicou a então "pneumonia desconhecida" como evento de monitoramento internacional. Em 22 de janeiro, o Centro de Operações de Emergência em Saúde 
Pública (COES) para gestão de resposta ao SUS foi ativado, em Nível 1 de alerta e sem casos suspeitos. Entre 18 e 27 de janeiro de 2020, foram notificados 10 casos de Covid10, dos quais apenas um foi considerado suspeito, já que os outros não cumpriram a definição de caso vigente à época ou apresentaram resultados positivos para outros vírus respiratórios. Em 3 de fevereiro, o Ministério da Saúde (MS) declarou Emergência em Saúde Pública de importância Nacional (ESPIN) (BRASIL, 2020c).

Em 26 de fevereiro de 2020, um mês após o primeiro caso suspeito, foi confirmado o 1 o caso de Covid19 no Brasil, na cidade de São Paulo, relativo a paciente proveniente de viagem à Europa (BRASIL..., 2020). A partir de março, vários casos foram confirmados em diferentes regiões (interior da Bahia, distrito Federal, Rio Grande do Sul). Todos eles de pessoas provenientes da Europa. A partir dessa confirmação, houve mudança no critério de caso, com a ampliação dos países que faziam parte do levantamento do histórico de viagem. A relação dos países que deveriam ser considerados na definição dos casos suspeitos foi ampliada, incluindo 8 novos países (dentre eles EUA e Itália) e foi sendo atualizada periodicamente, quando era confirmada a transmissão local da Covid19.

A ação de vigilância nos portos e aeroportos ficou restrita à distribuição de materiais informativos para os viajantes, não houve realização de barreiras sanitárias. Em 13 de março, o Ministério da Saúde recomendou isolamento voluntário de pessoas retornando do exterior, a contar da data de desembarque, bem como a suspensão dos cruzeiros turísticos. No entanto, essas medidas foram revistas no dia seguinte, em errata ao boletim (BRASIL, 2020a).

Nesse momento, já havia transmissão sustentada em 2 cidades (RJ e SP) e transmissão local em 2 estados (Bahia e São Paulo). Uma semana depois, a situação avançou rapidamente e, em 20 de março, 23 dias após a confirmação do primeiro caso, o Ministério da Saúde declarou estado de transmissão comunitária em todo o território nacional (BRASIL, 2020d).

Em relação aos exames laboratoriais, todos os Laboratórios Centrais dos estados e Distrito Federal foram capacitados para investigação epidemiológica laboratorial através da realização do RT PCR (reação da transcriptase reversa, seguida de reação em cadeia da polimerase), mas apenas 3 estados contavam com testagem automatizada. (MINISTÉRIO DA SAÚDE, 2020b). Em 23 de março, o MS anunciou a aquisição de cerca de 23 milhões de testes RT PCR para diagnosticar casos graves nos hospitais e casos leves por amostragem em unidades sentinelas, com previsão de entrega nos meses subsequentes. Além disso, anunciou a utilização de testes rápidos (sorologia) para detecção da Covid19 entre profissionais de saúde e a realização de estudo de soroprevalência de base populacional.

\section{EVIDÊNCIAS DAS DIFICULDADES NA VIGILÂNCIA DA COVID19}

Até o dia 8 de abril, o Brasil apresentou mais de 15 mil casos confirmados de Covid19 e 800 óbitos. $\mathrm{O}$ crescimento médio diário foi inferior às projeções realizadas com base na expansão da epidemia em outros países, que estimaram que o número de casos dobraria a cada 3 dias (MINISTÉRIO DA SAÚDE, 2020a). Quando comparado o crescimento dos casos no Brasil a conjunto de países e com a projeção de aumento de $33 \%$ de casos por dia, pode-se observar que a evolução dos casos de Covid19 tem se dado abaixo desses parâmetros (Figura $1)$. 
ISSN 2596-3317 - DOI 10.14295/aps.v2i1.70

Turci, M. A.; Holliday, J. B.; Oliveira, N. C. V. C.

Figura 1 - Casos confirmados de Covid19 no Brasil, outros países e projeção a partir do caso 50*.

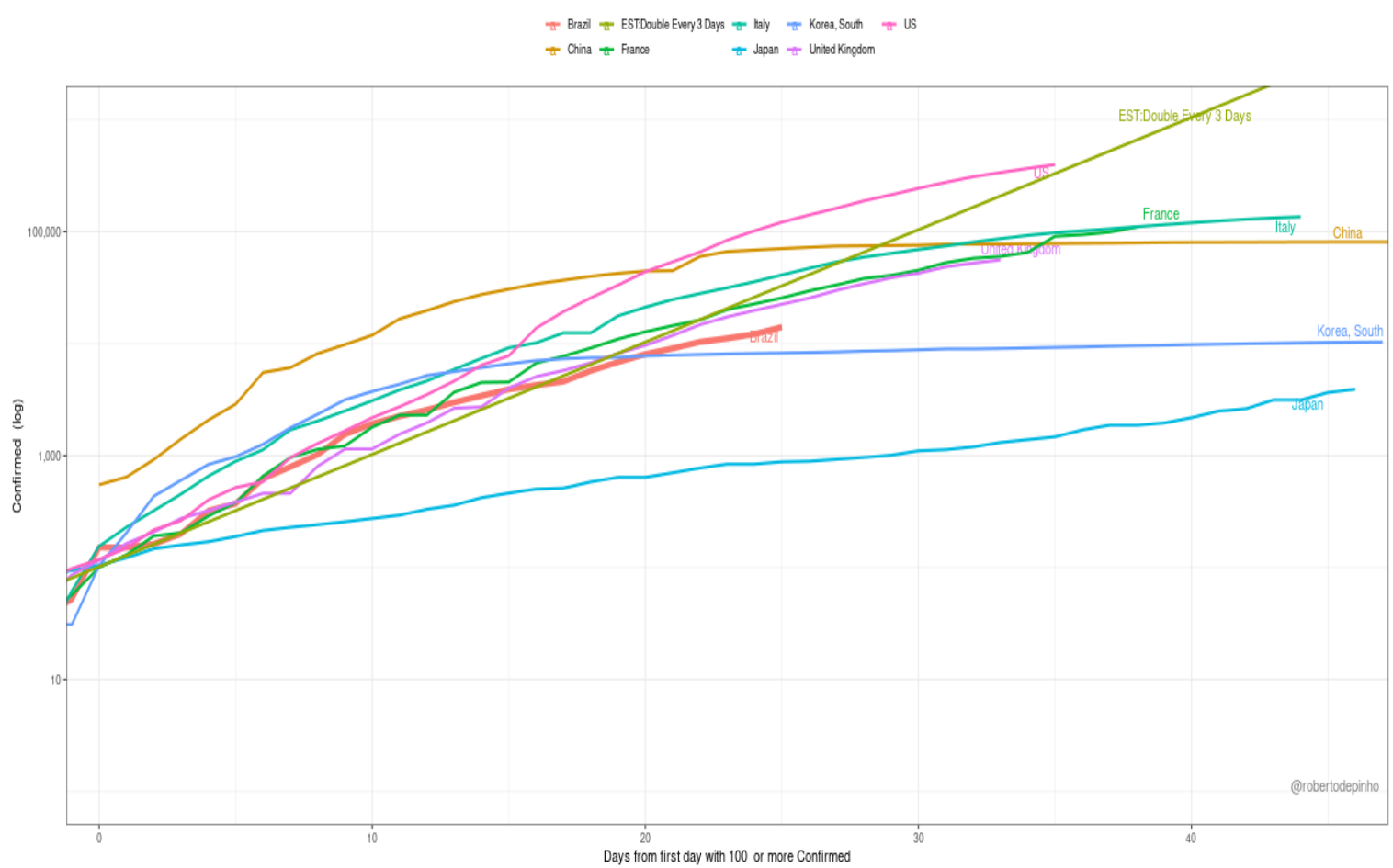

* escala logarítmica

Fonte: (UESC, 2020) dados coletados em 8 de março de 2020

O mesmo se observou quando analisados os brasileira seguiu tendência inferior à projeção casos do Brasil e estados (Figura 2). Em torno do de duplicação dos casos a cada 3 dias. 22 ㅁia após a confirmação do 50 으 caso, a curva

Figura 2 - Casos confirmados de Covid19 no Brasil e estados, e projeção a partir do caso 50.

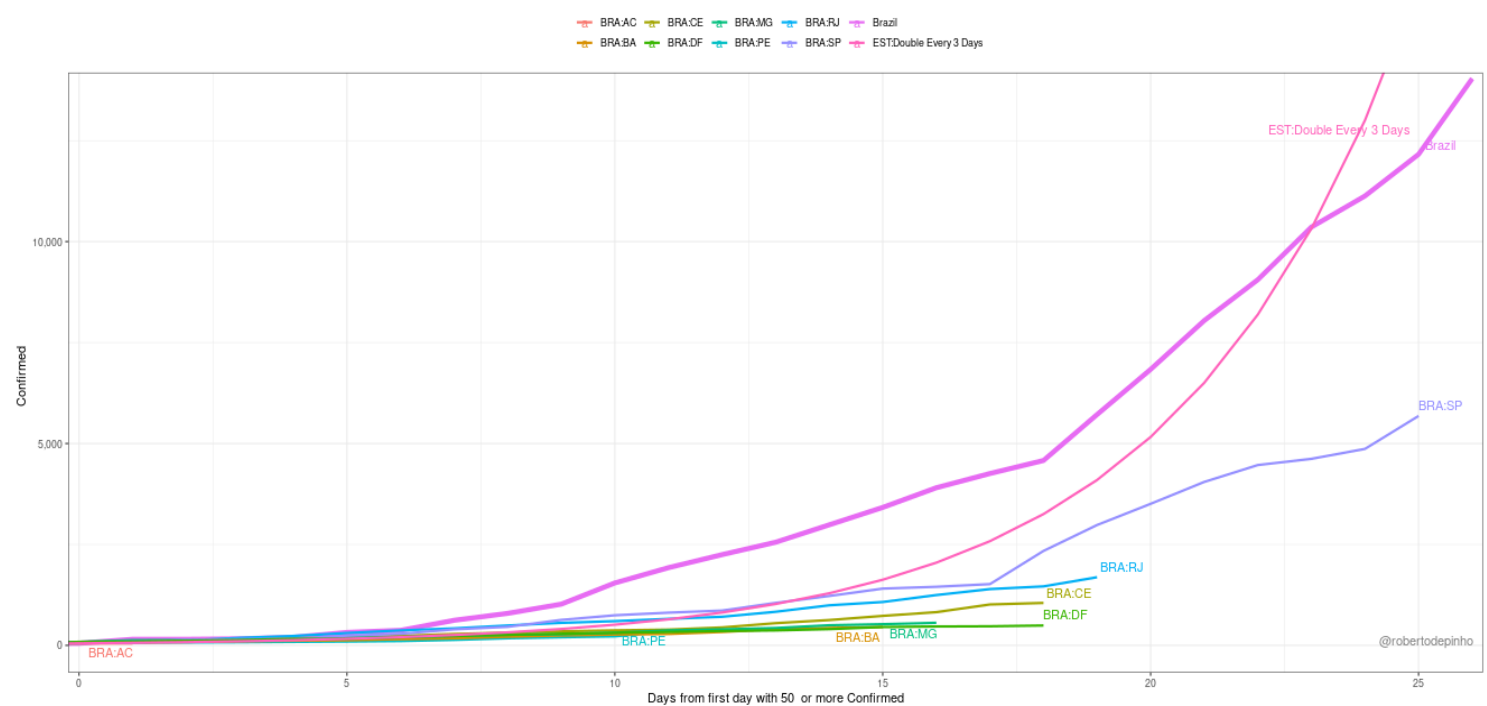

Fonte: (UESC, 2020) dados coletados em 8 de março de 2020

(c) 
Estimativas com base na epidemia em Wuhan, na China, dão conta de que cerca de $86 \%$ das infecções pelo Sars-Cov-2 não foram documentadas (LI, R. et al., 2020). Se aplicadas no Brasil, poderia se estimar que o país estaria com mais de 110 mil casos da doença no início de abril. Algumas situações podem ajudar a compreender que a escala da transmissão do vírus não pôde ser dimensionada de forma oportuna. O primeiro caso de Covid-19 de Belo Horizonte, por exemplo, foi confirmado em 16 de março. No dia seguinte, foi confirmada transmissão comunitária no município. Ou seja, em 48 horas, o município saiu da situação de não apresentar nenhum caso para a de transmissão sustentada (COES, 2020).

O caso do estado de Minas Gerais é emblemático. O Gráfico 1 mostra o número de casos confirmados, descartados e suspeitos, sendo que o total representa os casos notificados. A proporção de casos confirmados em relação aos notificados foi de menos de $1 \%$, enquanto os descartados ficaram em torno de $7 \%$. A proposta da vigilância da Covid19 é que sejam testados apenas os casos graves, então pode-se inferir que boa parte dos mais de $50 \mathrm{mil}$ casos notificados em Minas Gerais não serão sequer testados.

Gráfico 1 - Número de casos suspeitos, descartados e confirmados de Covid19 em Minas Gerais, de março a abril de 2020 .

60000

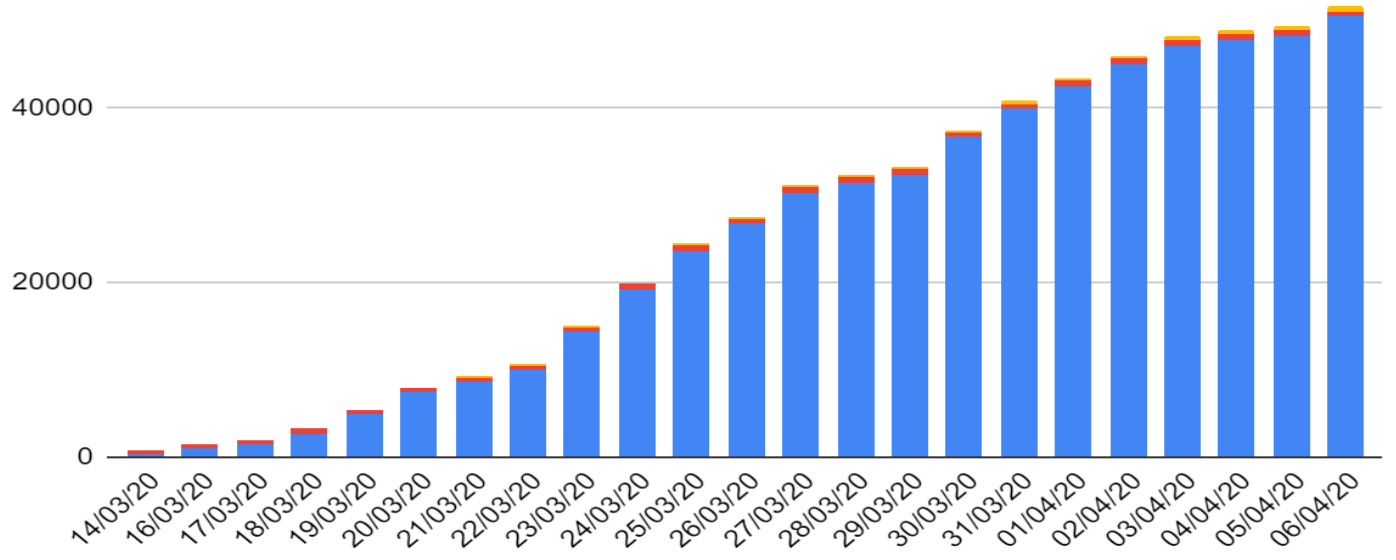

* Casos suspeitos (barra azul), casos descartados (barra vermelha) e casos confirmados (barra amarela)

Fonte: SES/MG (SECRETARIA DE SAÚDE-MG, 2020)

Dados trabalhados pelos autores

Outras evidências sugerem que a circulação do Sars-Cov-2 pode estar maior do que o atualmente estimado. Dados do Sistema de Monitoramento de casos reportados de Síndrome Respiratória Aguda Grave (SRAG) hospitalizados (InfoGripe) apontaram que o número de internações por SRAG foi quase 10 vezes maior em março de 2020 em comparação ao mesmo período do ano anterior, com uma mudança no perfil etário: o aumento das hospitalizações entre idosos (FIOCRUZ, 2020). Esse aumento já pode estar associado ao novo coronavírus. Esses dados são corroborados pelos provenientes do MS, que mostram que até a semana epidemiológica 15 foram realizadas cerca de 35 mil hospitalizações por SRAG no Brasil, com um incremento de $277 \%$ em 2020 em relação a 2019, em especial a partir da semana epidemiológica 10 (MINISTÉRIO DA SAÚDE, 2020c). 
O primeiro óbito confirmado por Covid19 data de 16 de março, mas rumores de incremento de óbitos por doenças respiratórias não registrados como decorrentes da Covid19 foram frequentes durante o mesmo mês. Levantamento realizado a partir da plataforma de registros civis no Brasil mostrou que, ao contrário da tendência observada nos meses de janeiro (101.470 em 2019 e 101.183 em 2020) e fevereiro (85.542 em 2019 e 84.951), em que os óbitos no Brasil em 2020 ocorreram em menor número que em 2019, no mês de março esse quadro foi invertido: ocorreram 2 mil óbitos a mais em 2020 (90.615 em 2019 e 92.481) (ARPEN BRASIL, 2020a). Visando dar mais transparência aos dados de registros de óbitos, a Associação Nacional dos Registradores de Pessoas Naturais (Arpen-Brasil) disponibilizou plataforma na área do Portal da Transparência do Registro Civil, que reúne informações dos cartórios de registro civil de todo o país, com atualização em tempo real sobre os óbitos registrados com confirmação ou suspeita da Covid19 (ARPEN BRASIL, 2020b). Dessa forma, esse se tornou um dispositivo mais ágil do que o Sistema de Informações sobre Mortalidade do SUS (SIM), cujas bases de dados nacionais se tornam públicas com hiato de dois anos. A demora na liberação dos resultados dos exames é um fator que tem determinado a dificuldade em dimensionar a letalidade da doença no país (RESULTADO..., 2020). Os óbitos apresentados pelo MS são organizados pela data de confirmação e não pela ocorrência, dificultando a leitura correta do cenário.

\section{As LACUNAS dA VIGILÂNCIA E AS}

\section{POSSIBILIDADES PARA A APS}

O principal motivo de críticas ao processo de vigilância tem sido baixa realização de exames. Mas as características do vírus e o perfil dos casos índices; o modelo de vigilância epidemiológica das doenças respiratórias, sua gestão e estágio de implementação; bem como o contexto do país podem ter sido determinantes para que o cenário em relação à transmissão da Covid19 esteja ainda turvo quase dois meses após a confirmação do primeiro caso no Brasil.
O Sars-Cov-2 é um agente patogênico de alta transmissibilidade. Estudos recentes revelam que a transmissão pode ocorrer também por bioaerossóis formados diretamente pela expiração dos pacientes, dificultando medidas preventivas (LEUG et al., 2020; LIU et al., 2020a; SANTARPIA et al., 2020). O vírus possui baixa patogenicidade, o que faz com que seus portadores circulem sem saber de sua condição (LI, R. et al., 2020), além de poder ser transmitido por assintomáticos (AGUILAR et al., 2020) e durante o período de incubação (LI, P. et al., 2020). Essas características limitam a capacidade dos serviços de saúde de identificar os casos de infecção. Tornam também de baixo impacto as medidas de isolamento de sintomáticos, amplamente preconizadas no início da epidemia (BRASIL, 2020a).

A baixa virulência e letalidade entre pacientes jovens, aliada à história natural da Covid, que mostra que os pacientes começam a perceber os sintomas de agravamento (dificuldade em respirar) em torno do 50 dia, com hospitalização em torno do 10 o dia, pode ter feito com que a magnitude da transmissão só tenha sido percebida quando os casos graves começaram a ocupar leitos hospitalares (ZHOU et al. 2020). Todos esses aspectos da Covid nos permitem compreender o fato da Atenção Primária à Saúde não ter participado de forma importante do início da identificação da doença no país, apesar de sua capilaridade no território nacional.

Como é esperado no caso de uma pandemia, os primeiros casos notificados no Brasil foram alóctones. Enquanto o mundo voltava suas preocupações aos países asiáticos, em especial à China, a doença iniciava sua curva ascendente em diversos países europeus e nos EUA. Foi exatamente desses países que vieram os primeiros casos da Covid. Dado o perfil socioeconômico desses indivíduos, não seria um erro supor que as primeiras unidades de saúde a receberem os casos estivessem no setor privado, o que levou o Ministro da Saúde a afirmar que "a doença chegou ao Brasil pelas classes mais altas" (CORONAVÍRUS..., 2020a). Foram emblemáticos os casos do Distrito 
Federal (MINISTÉRIO..., 2020) e de São Paulo (HOSPITAL..., 2020). Há muito se discute a pouca eficiência da notificação compulsória na vigilância epidemiológica, em especial no caso de doença emergente (HAMMANN; LAGUARDIA, 2000). A vigilância epidemiológica do SUS poderia ter lançado mão, de forma direcionada, de vigilância ativa em laboratórios e serviços de assistência privados desde a primeira notificação, ainda em janeiro. Mas apenas em abril de 2020 o MS recomendou essa ação (MINISTÉRIO DA SAÚDE, 2020e). As fiscalizações sanitárias, bem como os processos de acreditação, realizados nos hospitais privados, deveriam dar justa dimensão à verificação da estrutura e funcionamento dos Núcleos de Vigilância Epidemiológica, mas, para isso, se faz necessária a integração entre as ações das vigilâncias em saúde no SUS.

A notificação da Covid-19 se apresenta como um problema a parte. As definições de caso suspeito, como esperado, foram sendo alteradas conforme a situação de transmissão se modificava. Até a declaração de transmissão comunitária, a lista de países com transmissão local era atualizada periodicamente. Em determinado momento, foram definidos três critérios de caso diferentes num período de 20 dias, e no presente momento, coexistem dois tipos de orientações de manejo: as do Guia de Vigilância Epidemiológica (MINISTÉRIO DA SAÚDE, 2020e) e as do Protocolo de Manejo Clínico do Coronavírus na APS 7ạ versão (SAPS, 2020f). As plataformas de notificação também sofreram modificações ao longo do processo, três delas num período de 10 dias, estando vigente a $3^{a}$ plataforma. Por mais que os meios eletrônicos favoreçam o acesso à informação, é preocupante o volume de alterações ocorridas em tão pouco tempo, especialmente em relação às plataformas de notificação. Não é possível saber se essas mudanças chegaram em tempo oportuno nos mais de 5,5 mil municípios do país e seus quase 320 mil estabelecimentos de saúde. A coexistência de diversos critérios e plataformas pode ter gerado graves falhas no sistema de VE, em particular nos serviços de APS, e resultado em subnotificações, cuja magnitude é difícil de ser estimada. Pode ter ainda confundido a própria operacionalização das ações de controle pelos municípios e dificultado a comunicação com a rede privada.

A ineficiência da notificação compulsória comprometeu a realização de uma das formas mais eficientes de controle nas fases iniciais da epidemia, que é o rastreamento e vigilância dos contatos. Esse método foi amplamente utilizado na China (WHO, 2020b) e em Singapura (CORONAVÍRUS..., 2020b). Essa ação poderia ter sido delegada às equipes de atenção primária no Brasil, mas com a rápida expansão dos casos, a estratégia deixou de ter função no controle da expansão dos casos.

São inúmeras as dúvidas quanto aos números oficiais. O Centro de Informações Estratégicas em Vigilância em Saúde (CIEVS) do MS utiliza a detecção digital de rumores, a partir do monitoramento de painel desenvolvido por meio da ferramenta EIOS (Epidemic Intelligence from Open Sources). Apesar da baixa especificidade, essa ferramenta se mostra útil para que o sistema de saúde possa perceber a ocorrência de eventos que ainda não puderam ser medidos pelas ferramentas tradicionais (BRASIL, 2020b). Estudo realizado em Santa Catarina demonstrou que rumores sobre dengue, chikungunya, zika, Aedes aegypti e microcefalia estiveram relacionados ao número de casos suspeitos, confirmados ou descartados dessas doenças no estado (KLEIN; GUIDI; TEZZA, 2017). Dessa forma, essas estratégias de monitoramento poderiam ser usadas para indicar as localidades que deixam a situação de epidemias localizadas para aceleração descontrolada, em especial numa realidade de baixa testagem.

A partir da declaração de transmissão comunitária no Brasil, a Covid19 passou a ser tratada no contexto da vigilância das síndromes respiratórias. No Brasil, ela acontece por meio da vigilância sentinela de influenza, composta por Unidades Sentinelas para registro de informação de casos de Síndrome Gripal (SG) e Síndrome Respiratória Aguda Grave (SRAG) previamente cadastradas no Cadastro Nacional de Estabelecimentos de Saúde (CNES) e Sistema de Informação de Vigilância Epidemiológica da 
Gripe (SIVEP-Gripe) e da vigilância universal da SRAG. A vigilância de Síndrome Gripal (SG) em Unidades Sentinelas ocorre no país desde 2000, tendo como objetivo principal a identificação dos vírus respiratórios em circulação no país. Desde a pandemia de influenza pelo vírus $\mathrm{A}$ (H1N1), em 2009, a vigilância epidemiológica da influenza conta com a notificação universal de SRAG de casos hospitalizados e de óbitos. (MINISTÉRIO DA SAÚDE, 2015)

São inúmeros os episódios de demonstram que a gravidade da Covid19 foi subestimada por autoridades e profissionais de saúde. Isso dificultou a identificação precoce dos casos e vem dificultando a implementação das medidas de controle universalmente indicadas, colocando em risco as possibilidades de mitigação dos danos pessoais, sociais e sanitários. A crença de que a doença poderia ter comportamento diferente num país tropical não encontrava sustentação nas evidências. A sua trajetória no mundo e o número de vidas ceifadas tornam essa postura incompreensível. A contribuição da APS no delineamento da vigilância à Covid-19 proposto para o país se limita à notificação das Síndromes Gripais e à identificação e encaminhamento de casos graves. Lana et al., 2020 questionaram se o país estava preparado para a chegada do Sars-Cov-2, principalmente diante da redução dos investimentos no SUS praticada pelas políticas de austeridade. $O$ que foi visto até o momento mostra que mesmo diante da experiência e robustez do sistema de vigilância, ainda há muito a se construir.

\section{REFERÊNCIAS BIBLIOGRÁFICAS}

AGUILAR, Jacob et al. Investigating the impact of asymptomatic carriers on COVID-19 Transmission. MedRxiv, Nebraska, mar. 2020. DOI: 10.1101/2020.03.18.20037994. Disponível em:

https://www.medrxiv.org/content/10.1101/20

20.03.18.20037994v3. Acesso em: 03 de abr. 2020.
ARPEN BRASIL. Registro Civil, 2020a. Página

inicial. Disponível em: https://registrocivil.org.br/. Acesso em: 09 de abr. 2020.

ARPEN BRASIL. Registro Civil, 2020b. Portal da transparência.

https://transparencia.registrocivil.org.br/especi al-covid. Acesso em: 09 de abr. 2020.

BOLETIM INFORMATIVO DO COES MINAS COVID-19. Boletim informativo diário, Belo Horizonte. 17 de mar. 2020. Disponível em: https://www.saude.mg.gov.br/images/noticias _e_eventos/000_2020/Coronav\%C3\%ADrus/BO LETIM_COES_COVID_MG_19_-_17-03-

2020.pdf. Acesso em: 08 de abr. 2020.

BRASIL confirma primeiro caso do coronavírus. Folha de S. Paulo, São Paulo, 25 de fev. 2020. Disponível em: https://www1.folha.uol.com.br/equilibrioesaud e/2020/02/brasil-confirma-primeiro-caso-donovo-coronavirus.shtml. Acesso em: 01 de abr. 2020.

BRASIL. Ministério da Saúde. Guia de Vigilância em Saúde. -3 ed. - Brasília, 2019. Disponível em: https://bvsms.saude.gov.br/bvs/publicacoes/g uia_vigilancia_saude_3ed.pdf. Acesso em: 08 de abr. 2020.

BRASIL. Ministério da Saúde. Doença pelo Coronavírus 2019. COVID-19: boletim epidemiológico, Brasília, n. 5, mar. 2020a. Disponível em: http://maismedicos.gov.br/images/PDF/2020_ 03_13_Boletim-Epidemiologico-05.pdf. Acesso em: 06 de abr. 2020.

BRASIL. Ministério da Saúde. Infecção Humana pelo Novo Coronavírus (2019-nCoV). COVID-19: boletim epidemiológico, Brasília, n. 1, jan. 2020b. Disponível em: https://www.saude.gov.br/images/pdf/2020/fe vereiro/04/Boletim-epidemiologico-SVS04fev20.pdf. Acesso em: 06 de abr. 2020. 
BRASIL. Ministério da Saúde. Portaria MS no 188. Declara Emergência em Saúde Pública de importância Nacional (ESPIN) em decorrência da Infecção Humana pelo novo Coronavírus (2019nCoV). Diário Oficial da União, Brasília, n. 24, 03 de fev. 2020c. Disponível em: http://www.in.gov.br/en/web/dou/-/portarian-188-de-3-de-fevereiro-de-2020-241408388. Acesso em: 07 de abr. 2020.

BRASIL. Ministério da Saúde. Portaria MS no 454. Declara, em todo o território nacional, o estado de transmissão comunitária do coronavírus (COVID-19). Diário Oficial da União, Brasília, n. 55, 20 de mar. 2020d. Disponível em: http://www.in.gov.br/en/web/dou/-/portarian-454-de-20-de-marco-de-2020-249091587.

Acesso em: 01 de abr. 2020.

BRASIL. Ministério da Saúde. Portaria MS no 1.378. Regulamenta as responsabilidades e define diretrizes para execução e financiamento das ações de Vigilância em Saúde pela União, Estados, Distrito Federal e Municípios, relativos ao Sistema Nacional de Vigilância em Saúde e Sistema Nacional de Vigilância Sanitária. Diário Oficial da União, Brasília, 09 de jul. 2013. Disponível em: https://bvsms.saude.gov.br/bvs/saudelegis/gm /2013/prt1378_09_07_2013.html. Acesso em: 01 de abr. 2020.

CORONAVÍRUS ainda não chegou aos "bairros operários", diz ministro. R7, 03 de abr. 2020. Disponível em: https://noticias.r7.com/saude/coronavirusainda-nao-chegou-aos-bairros-operarios-dizministro-03042020. Acesso em: 09 de abr. 2020.

CORONAVIRUS: The detectives racing to contain the virus in Singapore. BBC News, Singapura, 19 de mar. 2020. Disponível em: https://www.bbc.com/news/world-asia51866102. Acesso em: 09 de abr. 2020.

DAWOOD, Fatimah et al. Estimated global mortality associated with the first 12 months of
2009 pandemic influenza A H1N1 virus circulation: a modelling study. The Lancet Infectious Diseases, Atlanta, v. 12, p. 687-695, set. 2012. DOI: 10.1016/S1473-3099(12)70121$4 . \quad$ Disponível em: https://www.ncbi.nlm.nih.gov/pubmed/22738 893. Acesso em: 01 de abr. 2020.

DOREMALEN, Neeltje Van et al. Aerossol and Surface Stability of SARS-CoV-2 as Compared with SARS-CoV-1. The New England Journal of Medicine, Massachusetts, mar. 2020. DOI: 10.1056/NEJMc2004973. Disponível em: https://www.nejm.org/doi/full/10.1056/NEJMc 2004973. Acesso em: 01 de abr. 2020.

FIOCRUZ. InfoGripe: Monitoramento de casos de Síndrome Respiratória Aguda Grave (SARG) hospitalizados, 2020. Disponível em: http://info.gripe.fiocruz.br/. Acesso em: 09 de abr. 2020.

FERGURSON, Neil et al. Impact of nonpharmaceutical interventions (NPIs) to reduce COVID19 mortality and healthcare demand. Imperial College COVID-19 Response Team, Londres, mar. 2020. DOI: 10.25561/77482. Disponível em: https://www.imperial.ac.uk/media/imperialcollege/medicine/sph/ide/gidafellowships/Imperial-College-COVID19-NPImodelling-16-03-2020.pdf. Acesso em: 06 de abr. 2020.

HAMMANN, Edgar Merchán; LAGUARDIA, Josué. Informe Epidemiológico do SUS, Brasília, v. 9 , n. 3, p. 211-219, set. 2000. DOI: 10.5123/s0104-16732000000300006.

Disponível em: http://scielo.iec.gov.br/scielo.php?pid=S0104$16732000000300006 \&$ script=sci_arttext $\&$ tlng $=$ pt. Acesso em: 01 de abr. 2020.

KAMPF, Günter et al. Persistence of coronaviruses on inanimate surfaces and their inactivation with biocidal agentes. Journal of Hospital Infection, Alemanha, v. 104, p. 246- 
251, jan. 2020. DOI: 10.1016/j.jhin.2020.01.022.

Disponível em: https://www.journalofhospitalinfection.com/ar ticle/S0195-6701(20)30046-3/pdf. Acesso em: 01 de abr. 2020.

KLEIN, Gisiela Hasse; GUIDI, Pedro; TEZZA, Rafael Tezza. Big Data e mídias sociais: monitoramento das redes como ferramenta de gestão. Saúde e Sociedade, São Paulo, v. 26, n. 1, p. 208-217, 2017. DOI:_10.1590/s010412902017164943. Disponível em: http://www.scielo.br/scielo.php?pid=S0104$12902017000100208 \&$ script=sci_abstract $\&$ tIng =pt. Acesso em: 02 de abr. 2020.

LANA, Raquel Martins et al. Emergência do novo coronavírus (SARS-CoV-2) e o papel de uma vigilância nacional em saúde oportuna e efetiva. Cadernos de Saúde Pública, Rio de Janeiro, v. 36 , n. 3, p. 01-05, 2020. DOI: 10.1590/0102311x00019620. Disponível em: http://www.scielo.br/pdf/csp/v36n3/16784464-csp-36-03-e00019620.pdf. Acesso em: 09 de abr. 2020.

LAUER, Stephen et al. The incubation period of coronavírus disease 2019 (COVID-19) from publicly reported confirmed cases: estimation and aplication. Annals of international Medicine, mar. 2020. DOI: 10.7326/M20-0504. Disponível em: https://annals.org/aim/fullarticle/2762808/inc ubation-period-coronavirus-disease-2019covid-19-from-publicly-reported. Acesso em: 06 de abr. 2020.

LEUG, Nancy et al. Respiratory virus shedding in exhaled breath and efficacy of face masks. Nature Medicine, Hong Kong, abr. 2020. DOI: 10.1038/s41591-020-0843-2. Disponível em: https://www.nature.com/articles/s41591-0200843-2\#article-info. Acesso em: 03 de abr. 2020.

LI, Peng et al. Transmission of COVID-19 in the terminal stage of incubation period: a familial cluster. International Journal of Infectious
Diseases, China, mar. 2020. DOI: 10.1016/j.ijid.2020.03.027. Disponível em: https://www.ijidonline.com/article/S12019712(20)30146-6/fulltext. Acesso em: 06 de abr. 2020.

LI, Ruiyun et al. Substantial undocumented infection facilitates the rapid dissemination of novel coronavirus (SARS-CoV2). American Association for the Advancement of Science, mar. 2020. DOI: 10.1126/science.abb3221. Disponível em: https://science.sciencemag.org/content/early/ 2020/03/24/science.abb3221/tab-pdf. Acesso em: 08 de abr. 2020.

LIU, Yuan et al. Aerodynamic Characteristics and RNA Concentration of SARS-CoV-2 Aerosol in Wuhan Hospitals during COVID-19 Outbreak. BioRxiv, Wuran, mar. 2020a. DOI: 10.1101/2020.03.08.982637. disponível em: https://www.biorxiv.org/content/10.1101/202 0.03.08.982637v1. Acesso em: 03 de abr. 2020.

LIU, Yuan et al. Viral dynamics in mild and severe cases Of COVID-19. The Lancet Infectious Desease, p. 1-2, mar. 2020b. DOI: 10.1016/S1473-3099(20)302332-2. Disponível em:

https://www.thelancet.com/journals/laninf/art icle/PIIS1473-3099(20)30232-2/fulltext. Acesso em: 05 de abr. 2020.

MINISTÉRIO DA SAÚDE. Coronavírus Brasil: Painel COVID-19, 2020a. Página inicial. Disponível em: https://covid.saude.gov.br/. Acesso em: 06 de abr. 2020.

MINISTÉRIO DA SAÚDE. Coronavírus: Vigilância epidemiológica de casos no Brasil e no mundo e medidas de saúde pública. Brasília: Centro de Operações de Emergência, mar. 2020b. 20 slides. Slides gerados a partir do software PowerPoint. Disponível em: https://docs.google.com/presentation/d/119xO 
ISSN 2596-3317 - DOI 10.14295/aps.v2i1.70

Turci, M. A.; Holliday, J. B.; Oliveira, N. C. V. C.

fneNXAtApaG45AFhhY4hqdOVuJz13zlsnsEx4gM /edit\#slide=id.g715acac511_76_0. Acesso em: 08 de abr. 2020.

MINISTÉRIO DA SAÚDE. Coronavírus: Vigilância epidemiológica de casos no Brasil e no mundo e medidas de saúde pública. Brasília: Centro de Operações de Emergência, 17 de mar. 2020c. 20 slides. Slides gerados a partir do software PowerPoint.

MINISTÉRIO DA SAÚDE. Guia de Vigilância Epidemiológica 3ạ ed.: Emergência de Saúde Pública de Importância Nacional pela Doença pelo Coronavírus 2019. Brasília, abr. 2020d. Disponível em: https://www.saude.gov.br/images/pdf/2020/A pril/06/GuiaDeVigiEp-final.pdf. Acesso em: 08 de abr. 2020

MINISTÉRIO DA SAÚDE. Vigilância sentinela Síndrome Gripal (SG) no Brasil. Brasília: MS, $2015 . \quad$ Disponível em: http://www.saude.pr.gov.br/arquivos/File/Vigil ancia_Sentinela_de_SG_no_Brasil_FINAL.pdf. Acesso em: 06 de abr. 2020. Acesso em: 09 de abr. 2020.

MINISTÉRIO: Hospital privado não pode transferir paciente com Coronavírus. Correio Braziliense, Brasília, 09 de mar. 2020. Disponível em:https://www.correiobraziliense.com.br/app /noticia/brasil/2020/03/09/internabrasil,833173/ministerio-hospital-privado-naopode-transferir-paciente-com-coronavi.shtml. Acesso em: 04 de abr. 2020.

MONTALVÃO, Elisa Alves. Avaliação de atributos do Sistema de Vigilância Sentinela da Síndrome Gripal no Município do Rio de Janeiro, Brasil, 2013-2014. 2017, Dissertação (Mestrado em Epidemiologia em Saúde Pública) - Escola Nacional de Saúde Pública Sérgio Arouca, na Fundação Oswaldo Cruz, Rio de Janeiro, 2017.

ORGANIZAÇÃO MUNDIAL DE SAÚDE. Pneumonia of unkow cause- CHINA. WHO,
Geneva, 05 de jan. 2020a. Disponível em: https://www.who.int/csr/don/05-january2020-pneumonia-of-unkown-cause-china/en/. Acesso em: 06 de abr. 2020.

ORGANIZAÇÃO MUNDIAL DE SAÚDE. Report of the WHO-China Joint Mission on Coronavirus Disease 2019 (COVID-19). WHO, Geneva, 24 fev. 2020b. Disponível em: https://www.who.int/docs/defaultsource/coronaviruse/who-china-joint-missionon-covid-19-final-report.pdf. Acesso em: 06 de abr. 2020.

ORGANIZAÇÃO PAN-AMERICANA DE SAÚDE. OMS afirma que COVID-19 é agora caracterizada como pandemia. Washington: OPAS, 11 de mar. 2020a. Disponível em: https://www.paho.org/bra/index.php?option=c om_content $\&$ view=article\&id=6120:omsafirma-que-covid-19-e-agora-caracterizadacomo-pandemia\&Itemid=812. Acesso em: 06 de abr. 2020.

ORGANIZAÇÃO PAN-AMERICANA DE SAÚDE. OMS declara emergência de saúde pública de importância internacional por surto de novo coronavírus. Washington: OPAS, 30 de jan. 2020b. Disponível em: https://www.paho.org/bra/index.php?option=c om_content\&view=article\&id=6100:omsdeclara-emergencia-de-saude-publica-deimportancia-internacional-em-relacao-a-novocoronavirus\&Itemid=812. Acesso em: 06 de abr. 2020.

ORGANIZAÇÃO PAN-AMERICANA DE SAÚDE. OMS divulga lista de doenças e patógenos prioritários para pesquisa e desenvolvimento em 2018. Washington: OPAS, 14 de fev. 2018. Disponível em: https://www.paho.org/bra/index.php?option=c om_content\&view=article\&id=5595:omsdivulga-lista-de-doencas-e-patogenosprioritarios-para-pesquisa-e-desenvolvimentoem-2018\&Itemid=812. Acesso em: 06 de abr. 2020. 
OMS quer testes e isolamento de casos suspeitos para conter o COVID-19. Portal EBC, 16 de mar. 2020. Disponível em: https://agenciabrasil.ebc.com.br/saude/noticia /2020-03/oms-recomenda-testes-e-isolamentode-casos-suspeitos-para-conter-covid-19.

Acesso em: 06 de abr. 2020.

RESULTADO de teste de COVID-19, só um mês depois do enterro. Folha de S. Paulo, São Paulo, 03 de abr. 2020. Disponível em: https://piaui.folha.uol.com.br/resultado-deteste-de-covid-19-so-um-mes-depois-doenterro/. Acesso em: 04 de abr. 2020.

RUSSEL, Timothy et al. Estimating the infection and case fatality radio for COVID-19 using ageadjusted data from teh outbreak on the Diamond Princess cruise ship. MedRxiv, Londres, mar. 2020. DOI: 10.2807/15607917.ES.2020.25.12.2000256. Disponível em: https://www.medrxiv.org/content/10.1101/20 20.03.05.20031773v2. Acesso em: $06 \mathrm{de} a b r$. 2020.

SANTARPIA, Joshua et al. Transmission Potential of SARS-CoV-2 in Viral Shedding Observed at the University of Nebraska Medical Center. MedRxiv, Nebraska, mar. 2020. DOI: 10.1101/2020.03.23.20039446. Disponível em: https://www.medrxiv.org/content/10.1101/20 20.03.23.20039446v2. Acesso em: 03 de abr. 2020.

SANTOS, Silvone Santa Bárbara da Silva et al. Avaliação da capacidade de gestão descentralizada da vigilância epidemiológica no estado da Bahia. Ciência de Saúde coletiva, v. 17, n. 4, p.873-882, 2012. DOI: 10.1590/S141381232012000400010 (SANTOS et al., 2012)

SECRETARIA DE ATENÇÃO PRIMÁRIA À SAÚDE. Protocolo de manejo clínico do coronavírus (COVID-19) na atenção primária à saúde, 7a ed. SAPS, Brasília, abr. 2020.

SECRETARIA DE SAÚDE DE MINAS GERAIS. Secretaria de Estado de Saúde, 2020. Informe
Epidemiológico Coronavírus. Disponível em: https://www.saude.mg.gov.br/coronavirus. Acesso em: 06 de abr. 2020.

UNIVERSIDADE ESTADUAL DE SANTA CRUZ. Vizcovid, 2020. Página inicial. Disponível em: http://vizcovid.ccam.uesc.br:3838/vizcovid/das hboard/. Acesso em: 09 de abr. 2020.

VASCONCELOS, Camila Soares de; FRIAS, Paulo Germano de. Avaliação da Vigilância da Síndrome Gripal: estudo de casos em unidade sentinela. Saúde debate, Rio de Janeiro, v. 41, p. 259-274, mar. 2017. DOI: 10.1590/010311042017 s19.

WORLDOMETER. Coronavirus Death Tolls, 2020. Disponível em: https://www.worldometers.info/coronavirus/c oronavirus-death-toll/. Acesso em: 06 de abr. 2020.

WU, Di et al. The SARS-CoV-2 Outbreak: What We Know. International Journal of Infectious Diseases, China, mar. 2020. DOI: 10.1016/j.ijid.2020.03.004. Disponível em: https://www.ncbi.nlm.nih.gov/pubmed/32171 952. Acesso em: 06 de abr. 2020.

ZHOU, Fei et al. Clinical course and risk factors for mortality of adult inpatients with COVID-19 in Wuhan, China: a retrospective cohort study. The Lancet, v. 395, p. 1054-1062, mar. 2020. DOI: $\quad 10.1016 / \quad$ S0140-6736(20)30566-3. Disponível em: https://www.thelancet.com/action/showPdf?pi $\mathrm{i}=\mathrm{S} 0140-6736 \% 2820 \% 2930566-3$. Acesso em: 05 de abr. 2020. 